\title{
ANTICANCER RESEARCH International Journal of Cancer Research and Treatment
}

\section{Individual Genetic Variation Might Predict Acute Skin Reactions in Women Undergoing Adjuvant Breast Cancer Radiotherapy}

DELMY OLIVA $^{1,2}$, MATS NILSSON ${ }^{3,4}$, MICHAEL STRANDÉUS ${ }^{1}$, BENGT-ÅKE ANDERSSON ${ }^{2,5}$,

LENA SHARP ${ }^{6,7}$, NONGNIT LAYTRAGOON-LEWIN ${ }^{2,5}$ and FREDDI LEWIN ${ }^{1,2}$

${ }^{1}$ Department of Oncology, Ryhov County Hospital, Jönköping, Sweden;

${ }^{2}$ Department of Clinical and Experimental Medicine, Linköping University, Linköping, Sweden;

${ }^{3}$ Futurum-The Academy for Healthcare, Region Jönköping County, Jönköping, Sweden;

${ }^{4}$ Department of Medical and Health Sciences, Linköping University, Linköping, Sweden;

${ }^{5}$ Department of Laboratory medicine, Region Jönköping County, Jönköping, Sweden;

${ }^{6}$ Regional Cancer Centre, Stockholm-Gotland, Stockholm, Sweden;

${ }^{7}$ Department of Learning, Informatics, Management and Ethics, Karolinska Institute, Stockholm, Sweden 


\section{ANTICANCER RESEARCH International Journal of Cancer Research and Treatment}

\section{Editorial Board}

P. A. ABRAHAMSSON, Malmö, Sweden

B. B. AGGARWAL, Houston, $T X$, USA

T. AKIMOTO, Kashiwa, Chiba, Japan

P. Z. ANASTASIADIS, Jacksonville, FL, USA

A. ARGIRIS, San Antonio, TX, USA

J. P. ARMAND, Toulouse, France

V. I. AVRAMIS, Los Angeles, CA, USA

D.-T. BAU, Taichung, Taiwan, ROC

G. BAUER, Freiburg, Germany

E. E. BAULIEU, Le Kremlin-Bicetre, France

E. J. BENZ, Jr., Boston, MA, USA

J. BERGH, Stockholm, Sweden

F. T. BOSMAN, Lausanne, Switzerland

M. BOUVET, La Jolla, CA, USA

J. BOYD, Miami, FL, USA

G. BROICH, Monza, Italy

Ø. S. BRULAND, Oslo, Norway

J. M. BUATTI, lowa City, IA, USA

M. M. BURGER, Basel, Switzerland

M. CARBONE, Honolulu, HI, USA

C. CARLBERG, Kuopio, Finland

J. CARLSSON, Uppsala, Sweden

A. F. CHAMBERS, London, ON, Canada

P. CHANDRA, Frankfurt am Main, Germany

L. CHENG, Indianapolis, IN, USA

J.-G. CHUNG, Taichung, Taiwan, ROC

R. CLARKE, Washington, DC, USA

E. DE CLERCQ, Leuven, Belgium

W. DEN OTTER, Amsterdam, The Netherlands

E. P. DIAMANDIS, Toronto, ON, Canada

G. TH. DIAMANDOPOULOS, Boston, MA, USA

L. EGEVAD, Stockholm, Sweden

D. W. FELSHER, Stanford, CA, USA

J. A. FERNANDEZ-POL, Chesterfield, MO, USA

I. J. FIDLER, Houston, $T X$, USA

A. P. FIELDS, Jacksonville, $F L$, USA

H. FU, Atlanta, GA, USA

B. FUCHS, Zurich, Switzerland

D. FUCHS, Innsbruck, Austria

D. FUKUMURA, Boston, MA, USA

G. GABBIANI, Geneva, Switzerland

R. GANAPATHI, Charlotte, NC, USA

A. F. GAZDAR, Dallas, $T X$, USA

A. GIORDANO, Philadelphia, PA, USA

G. GITSCH, Freiburg, Germany

M. GNANT, Vienna, Austria

R. H. GOLDFARB, Guilford, CT, USA

A. HELLAND, Oslo, Norway

L. HELSON, Quakertown, PA, USA

R. HENRIKSSON, Umeå, Sweden

R. M. HOFFMAN, San Diego, CA, USA

S. C. JHANWAR, New York, NY, USA

J. V. JOHANNESSEN, Oslo, Norway

R. JONES, London, UK

B. KAINA, Mainz, Germany

P. -L. KELLOKUMPU-LEHTINEN, Tampere,

Finland

D. G. KIEBACK, Schleswig, Germany

R. KLAPDOR, Hamburg, Germany

H. KOBAYASHI, Bethesda, MD, USA

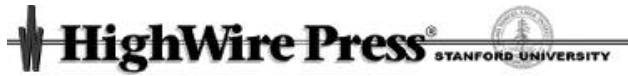

ISSN (print): 0250-7005

ISSN (online): 1791-7530

Editorial Office: International Institute of Anticancer Research, 1st km Kapandritiou-Kalamou Rd., Kapandriti, P.O. Box 22, Attiki 19014, Greece. Tel / Fax: +30-22950-53389.

S. D. KOTTARIDIS, Athens, Greece G. R. F. KRUEGER, Köln, Germany Pat M. KUMAR, Manchester, UK Shant KUMAR, Manchester, UK O. D. LAERUM, Bergen, Norway

F. J. LEJEUNE, Lausanne, Switzerland

S. LINDER, Linköping, Sweden

L. F. LIU, Piscataway, NJ, USA

D. M. LOPEZ, Miami, FL, USA

E. LUNDGREN, Umeå, Sweden

Y. MAEHARA, Fukuoka, Japan

J. MAHER, London, UK

J. MARESCAUX, Strasbourg, France

J. MARK, Skövde, Sweden

S. S. MARTIN, Baltimore, MD, USA

S. MITRA, Houston, TX, USA

S. MIYAMOTO, Fukuoka, Japan

S. MONCADA, Manchester, UK

M. MUELLER, Villingen-Schwenningen, Germany

F. M. MUGGIA, New York, NY, USA

M. NAMIKI, Kanazawa, Ishikawa, Japan

R. NARAYANAN, Boca Raton, FL, USA

K. NILSSON, Uppsala, Sweden

S. PATHAK, Houston, $T X$, USA

J.L. PERSSON, Malmö, Sweden

G. J. PILKINGTON, Portsmouth, UK

C. D. PLATSOUCAS, Norfolk, VA, USA

A. POLLIACK, Jerusalem, Israel

D. RADES, Lübeck, Germany

M. RIGAUD, Limoges, France

U. RINGBORG, Stockholm, Sweden

M. ROSELLI, Rome, Italy

S.T. ROSEN, Duarte, CA, USA

A. SCHAUER, Göttingen, Germany

M. SCHNEIDER, Wuppertal, Germany

J. SEHOULI, Berlin, Germany

A. SETH, Toronto, ON, Canada

G. V. SHERBET, Newcastle-upon-Tyne, UK

A. SLOMINSKI, Birmingham, AL, USA

G.-I. SOMA, Kagawa, Japan

G. S. STEIN, Burlington, VT, USA

T. STIGBRAND, Umeå, Sweden

T. M. THEOPHANIDES, Athens, Greece

P. M. UELAND, Bergen, Norway

H. VAN VLIERBERGHE, Ghent, Belgium

R. G. VILE, Rochester, MN, USA

M. WELLER, Zurich, Switzerland

J. WESTERMARCK, Turku, Finland

B. WESTERMARK, Uppsala, Sweden

Y. YEN, Taipei, Taiwan, ROC

M.R.I. YOUNG, Charleston, SC, USA

B. ZUMOFF, New York, NY, USA

G. J. DELINASIOS, Athens, Greece

Managing Editor and

Executive Publisher

J. G. DELINASIOS, Athens, Greece

Managing Editor (1981-2016)
U.S. Branch: Anticancer Research USA, Inc., 111 Bay Avenue, Highlands, NJ 07732, USA.

E-mails: Editorial Office: journals@iiar-anticancer.org Managing Editor: editor@iiar-anticancer.org

ANTICANCER RESEARCH supports: (a) the establishment and the activities of the INTERNATIONAL INSTITUTE OF ANTICANCER RESEARCH (IIAR; Kapandriti, Attiki, Greece); and (b) the organization of the International Conferences of Anticancer Research. The IIAR is a member of UICC. For more information about ANTICANCER RESEARCH, IIAR and the Conferences, please visit the IIAR website: www.iiar-anticancer.org

Publication Data: ANTICANCER RESEARCH (AR) is published bimonthly from January 1981 to December 2008 and monthly from January 2009. Each annual volume comprises 12 issues. Annual Author and Subject Indices are included in the last issue of each volume. ANTICANCER RESEARCH Vol. 24 (2004) and onwards appears online with Stanford University HighWire Press from April 2009.

Copyright: On publication of a manuscript in $A R$, which is a copyrighted publication, the legal ownership of all published parts of the paper passes from the Author(s) to the Journal.

Annual Subscription Rates 2018 per volume: Institutional subscription US\$ 1,898.00 (online) or US\$ 2,277.00 (print \& online). Personal subscription US\$ 897.00 (online) or US\$ 1,277.00 (print \& online). Prices include rapid delivery and insurance. The complete previous volumes of Anticancer Research (Vol. 1-37, 1981-2017) are available at $50 \%$ discount on the above rates.

Subscription Orders: Orders can be placed at agencies, bookstores, or directly with the Publisher. (e-mail: subscriptions@iiar-anticancer.org) Advertising: All correspondence and rate requests should be addressed to the Editorial Office.

Book Reviews: Recently published books and journals should be sent to the Editorial Office. Reviews will be published within 2-4 months.

Articles in ANTICANCER RESEARCH are regularly indexed in all bibliographic services, including Current Contents (Life Sciences), Science Citation Index, Index Medicus, Biological Abstracts, PubMed, Chemical Abstracts, Excerpta Medica, University of Sheffield Biomedical Information Service, Current Clinical Cancer, AIDS Abstracts, Elsevier Bibliographic Database, EMBASE, Compendex, GEOBASE, EMBiology, Elsevier BIOBASE, FLUIDEX, World Textiles, Scopus, Progress in Palliative Care, Cambridge Scientific Abstracts, Cancergram (International Cancer Research Data Bank), MEDLINE, Reference Update - RIS Inc., PASCAL-CNRS, InpharmaReactions (Datastar, BRS), CABS, Immunology Abstracts, Telegen Abstracts, Genetics Abstracts, Nutrition Research Newsletter, Dairy Science Abstracts, Current Titles in Dentistry, Inpharma Weekly, BioBase, MedBase, CAB Abstracts/Global Health Databases, Investigational Drugs Database, VINITI Abstracts Journal, Leeds Medical Information, PubsHub, Sociedad Iberoamericana de Información Científíca (SIIC) Data Bases.

Obtaining permission to reuse or reproduce our content: AR has partnered with Copyright Clearance Center (CCC) to make it easy to secure permissions to reuse its content. Please visit www.copyright.com and enter the title that you are requesting permission for in the 'Get Permission' search box. For assistance in placing a permission request, Copyright Clearance Center can be contacted directly at: Copyright Clearance Center, 222 Rosewood Drive, Danvers, MA 01923 USA. Phone: +1-978-7508400. Fax: +1-978-646-8600. E-mail: info@copyright.com.

The Editors and Publishers of ANTICANCER RESEARCH accept no responsibility for the opinions expressed by the contributors or for the content of advertisements appearing therein.

Copyright $@ 2018$, International Institute of Anticancer Research

(Dr. George J. Delinasios), All rights reserved.

D.T.P. BY IIAR

PRINTED BY ENTYPO, ATHENS, GREECE. PRINTED ON ACID-FREE PAPER 


\title{
Individual Genetic Variation Might Predict Acute Skin Reactions in Women Undergoing Adjuvant Breast Cancer Radiotherapy
}

\author{
DELMY OLIVA $^{1,2}$, MATS NILSSON ${ }^{3,4}$, MICHAEL STRANDÉUS ${ }^{1}$, BENGT-ÅKE ANDERSSON ${ }^{2,5}$, \\ LENA SHARP ${ }^{6,7}$, NONGNIT LAYTRAGOON-LEWIN ${ }^{2,5}$ and FREDDI LEWIN ${ }^{1,2}$ \\ ${ }^{1}$ Department of Oncology, Ryhov County Hospital, Jönköping, Sweden; \\ ${ }^{2}$ Department of Clinical and Experimental Medicine, Linköping University, Linköping, Sweden; \\ ${ }^{3}$ Futurum-The Academy for Healthcare, Region Jönköping County, Jönköping, Sweden; \\ ${ }^{4}$ Department of Medical and Health Sciences, Linköping University, Linköping, Sweden; \\ ${ }^{5}$ Department of Laboratory medicine, Region Jönköping County, Jönköping, Sweden; \\ ${ }^{6}$ Regional Cancer Centre, Stockholm-Gotland, Stockholm, Sweden; \\ ${ }^{7}$ Department of Learning, Informatics, Management and Ethics, Karolinska Institute, Stockholm, Sweden
}

\begin{abstract}
Adverse skin reactions during radiotherapy $(R T)$ are common. The aim of this study was to explore whether genetic variation might be linked to acute radiation skin reactions (ARSR). Materials and Methods: One hundred and nineteen women undergoing adjuvant $R T$ for breast cancer were included. The symptoms of itching, burning and irritation were self-reported twice using the visual analogue scale. Assessments used the Radiation Therapy Oncology Group scoring system for acute RT skin reaction (RTOG scale). Blood-based single nucleotide polymorphism (SNP) analysis was performed. Thirty SNPs of well-defined functional genes were investigated. Results: All women were assessed with ARSR. After RT, the women self-reported itching (n=97), burning ( $n=64)$ and irritation ( $n=96)$. Two SNPs in X-Ray Repair Cross Complementing 2 gene (XRCC2) rs2040639 and interferon gamma (IFNG) rs2069705 genes were found to be associated with ARSR. Conclusion: An association between two SNPs and ARSR was found. The possibility of using these SNPs as prognostic biomarkers for ARSR as tools to improve the care of patients needs further investigation.
\end{abstract}

Acute radiation skin reactions (ARSRs) are common in patients treated with radiotherapy (RT) (1). While adjuvant

Correspondence to: Delmy Oliva, Department of Oncology, Ryhov County Hospital, SE-551 85, Jönköping, Sweden. Tel: +46 0102426909, Fax: +46 0102422916, e-mail: delmy.oliva@rjl.se

Key Words: Radiotherapy, breast cancer, skin reactions, single nucleotide polymorphism.
RT for women with breast cancer (BC) is often well tolerated, ARSRs affect many of the patients in varying degrees. Most patients experience mild ARSR, with different degrees of erythema (2). A smaller proportion (20\%) experience more severe ARSR, with dry or moist desquamation which is often associated with discomfort, itching, pain and disturbed sleep patterns $(3,4)$. ARSR normally appears 1 to 2 weeks into the RT, accelerating during the treatment period and reaching a peak approximately 10 days after the completion of RT $(5,6)$.

Known risk factors for ARSR are treatment-related (such as RT dose, overall treatment time, irradiated volume, use of boost or bolus) (2) and patient-related (such as high body mass index and smoking) (7).

RT induces DNA damage leading to cell-cycle arrest and cell death (8). This can be particularly toxic to normal tissues since the timing of damage appearance can vary widely between different normal tissues and tumour (9). This in turn affects the skin, resulting in various reactions from redness to flaking of the skin and eruptions. The individual variations in ARSR suggest that genetic differences might underlie the different responses $(8,10)$.

Single nucleotide polymorphism (SNP) is the most common variation in DNA and may result in altered gene expression as well as different responses to external factors such as radiation and drug metabolism (11). Blood-based SNP analysis is simple, cost-effective and rapid. It can be undertaken before any treatment, utilizing common laboratory facilities. It is important to evaluate the possible role of SNPs as a prognostic biomarker in relation to the frequency and intensity of ARSR in women with BC in order to improve information and skin care strategies $(12,13)$. 
Different skin care products are in clinical use to reduce ARSR. Studies present conflicting results regarding the effects of topical agents $e . g$. steroids $(6,14,15)$ calendula cream $(4,16)$, and hyaluronic acid $(17,18)$.

The aim of this study was to explore whether the early signs of ARSR in patients with BC treated with adjuvant RT, as evaluated by patients and healthcare givers, might be linked to genetic variations.

\section{Materials and Methods}

Women who underwent adjuvant RT at the Department of Oncology, Ryhov County Hospital Jönköping, Sweden from February 2011 to May 2013 were included in this study. For patient characteristics, see Table I. As there were no previous data on the association between SNP and ARSR, it was not possible to perform any study power calculation before the study started. Instead this cohort study would serve as the foundation for power calculation in future studies.

The Regional Ethical Review Board approved the study (Dnr. 2010/331-31, December 2010). The women were informed verbally and in writing by an Oncology Research Nurse about the purpose and the procedures of the study. The participants were able to withdraw from the study at any time.

Participants. One hundred and thirty women of mainly Caucasian ethnicity, older than 18 years of age and scheduled for postoperative adjuvant RT after breast-conserving surgery were invited to participate. If they accepted, a written consent form was signed. Out of 130 consecutive women invited, five declined for personal reasons and six were not able to report their symptoms. Twenty-six of the women had previously been treated with chemotherapy and were also included in the analysis (fluorouracil, epirubicin and cyclophosphamide as first treatment followed by a taxane) (Figure 1). A complete dataset on the self-reported symptoms was recorded using data from the remaining 119 women.

Radiotherapy. The whole breast, clinical target volume (CTV) with $1 \mathrm{~cm}$ margin to planning target volume (PTV) was treated with two parallel opposing tangential fields using Varian Linacc $2100 \mathrm{CD}$, (Varian Medical Systems, Inc, Palo Alto, CA USA). Depending on the size of the breast, 6-MV or 6-MV combined with 15-MV photons in some fields, were chosen. The treatments were prescribed to the 95\% isodose according to International Commission on Radiation Units and Measurements (19), in a 3dimensional treatment planning system (Oncentra masterplan v 4.3; Elekta AB, Stockholm, Sweden). Areas of $90-105 \%$ were accepted. The absorbed dose was 50 Gy in 25 fractions given as one fraction per day, 5 days per week with an overall treatment time of 5 weeks. Gating was not used nor bolus. However, four patients were treated with a hypofractionated RT schedule $(20,21) 42,56$ Gy in 16 fractions, one fraction per day, 5 fractions per week.

Standard skin care protocol. At the Department, the standard skin care protocol recommends the use of topical corticosteroid $(0.1 \%$ Betamethasone cream) on the irradiated skin from the first sign of ARSR. The women were recommended to use the corticosteroid cream twice daily until 3 weeks past the completion of RT. If moist desquamation occurred, the use of corticosteroid was stopped, and patients were recommended to continue skin care with a hydrophilic
Table I. Clinical characteristics of the responding women.

\begin{tabular}{|c|c|}
\hline Characteristic & Value \\
\hline \multicolumn{2}{|l|}{ Age, n (\%) } \\
\hline$\leq 50$ Years & $15(13)$ \\
\hline$>50$ Years & $104(87)$ \\
\hline \multicolumn{2}{|l|}{ BMI, $\mathrm{kg} / \mathrm{m}^{2}$} \\
\hline Median (range) & $27(20-41)$ \\
\hline \multicolumn{2}{|l|}{ Smoking, n (\%) } \\
\hline Yes & $14(12)$ \\
\hline \multicolumn{2}{|l|}{ Tumour size, n (\%) } \\
\hline T0 & $1(1)$ \\
\hline $\mathrm{T} 1$ & $72(61)$ \\
\hline $\mathrm{T} 2$ & $24(20)$ \\
\hline $\mathrm{T} 3$ & $9(8)$ \\
\hline $\mathrm{T} 4$ & $1(1)$ \\
\hline Tis & $11(9)$ \\
\hline $\mathrm{T} 1 \mathrm{mi}$ & $1(1)$ \\
\hline \multicolumn{2}{|l|}{ Node stage, n (\%) } \\
\hline No & $82(69)$ \\
\hline N1 & $30(25)$ \\
\hline $\mathrm{N} 2$ & $7(6)$ \\
\hline \multicolumn{2}{|c|}{ Stage of disease, $\mathrm{n}(\%)$} \\
\hline 0 & $12(11)$ \\
\hline I & $52(43)$ \\
\hline IA & $7(6)$ \\
\hline IIA & $19(16)$ \\
\hline IIB & $17(14)$ \\
\hline IIIA & $11(9)$ \\
\hline IIIB & $1(1)$ \\
\hline \multicolumn{2}{|c|}{ Hormone receptor, n (\%) } \\
\hline $\mathrm{ER}^{+}$ & $100(94)$ \\
\hline $\mathrm{ER}^{-}$ & $6(6)$ \\
\hline $\mathrm{PgR}^{+}$ & $81(76)$ \\
\hline $\mathrm{PgR}^{-}$ & $25(24)$ \\
\hline \multicolumn{2}{|c|}{ HER2 status, n (\%) } \\
\hline Positive & $10(9)$ \\
\hline Negative & $96(91)$ \\
\hline \multicolumn{2}{|c|}{ Type of tumour, n (\%) } \\
\hline Ductal & $80(67)$ \\
\hline Lobular & $16(14)$ \\
\hline DCIS & $12(10)$ \\
\hline Other & $11(9)$ \\
\hline Total, n (\%) & $119(100)$ \\
\hline
\end{tabular}

BMI: Body mass index; DCIS: ductal carcinoma in situ; ER: oestrogen receptor; HER2: human epidermal growth factor receptor 2; PgR: progesterone receptor.

body lotion or cream. In addition, from the onset of RT a basic perfume-free moisturizing cream (Essex ${ }^{\circledR}$ MSD, Kenilworth, NJ, USA) was recommended to be used several times daily.

Assessment of the irradiated skin. Validated instruments for the evaluation of the irradiated skin were used. The original version of the Radiation Therapy Oncology Group (RTOG) scoring system for acute RT dermatitis was used to assess the irradiated skin (22). The research nurse assessed the ARSR twice during RT: 1 week after the start, as well as in the final week of RT. Itching, burning and irritation was assessed by the patient at the same time points, using a Visual Analog Scale (VAS) (scale of 0-10) (23). 


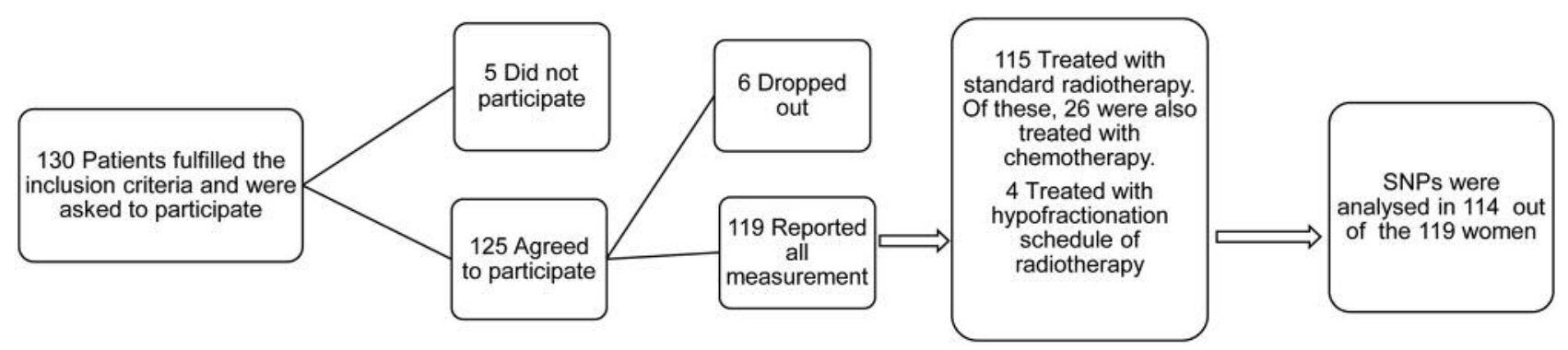

Figure 1. Flow chart of the study inclusion.

Blood samples. Venous blood $(30 \mathrm{ml})$ was drawn from each patient before the start of RT. High-molecular-weight DNA was extracted from the blood using MagNa Pure LC2.0 (Roche Diagnostic, F Hoffmann-La Roche, Rotkreuz, Switzerland). The quality and quantity of DNA were determined by Nanodrop ND-1000 spectrophotometer (ThermoFisher Scientific, Waltham, MA, USA) and confirmed by Pico green method using Quant-iT ${ }^{\text {TM }}$ Pico Green $^{\mathrm{TM}}$ dsDNA Assay Kit (ThermoFischer Scientific). The Pico Green fluorescence intensity was determined by Hidex Sense Microplate reader (Hidex Oy, Turku, Finland). DNA (250 ng) from each patient was used as the template for SNP analysis. The identification of the SNPs was performed by Illumina Golden Gate Genotyping assay at the SNP\&SEQ Technology Platform, Uppsala University, Sweden (http://www.genotyping.se).

Selection and analyses of SNPs. The candidate genes and their SNPs (Table II) were selected based on well-defined functions concerning DNA damage, DNA repair, cell cycle regulation, cell death and inflammation, the hypothesis being that individual difference in ARSR might in part depend on differences in these genes. Based on this, 30 related SNPs in 28 genes were studied.

Statistical analysis. Descriptive statistics, numbers, medians and percentages, were utilized for the background variables. The genotypic and allelic frequencies were quality checked. For SNPs, all included genotypes fulfilled the Hardy-Weinberg equilibrium (HWE, chi-squared test, $p<0.05$ ) as well as a minor allelic frequency $<5 \%$. Odds ratios and $95 \%$ confidence intervals were calculated for the influence of SNPs (exposure, e.g. A/A vs. G/G) on self-reported burning, itching and irritation (outcome e.g. irritation/no irritation).

This study originated as a pilot study and thus no study power calculation was made, since the number of patients was allocated from available resources at hand, before the start of the study. The smallest detectable effect with a patient population of 119 women was calculated afterwards. We found that an odds ratio $\geq 2.0$ when comparing the influence of SNPs on the self-reported outcomes would be statistically significant, with a $p$-value of at least 0.05 and estimated power of $90 \%$ would be statistically satisfactory. Since there were 30 SNPs from 28 candidate genes analysed, there was a risk of false-positive test results, therefore the Hochberg method (24) was used to correct for multiple testing. In Table II, the $p$-values presented are after correction for multiple testing.

In order to evaluate which SNPs to use in the final risk analysis, the set of alleles (e.g. A/A vs. G/G) were associated with the distribution of self-reported inconvenience (e.g. irritation/no irritation) from treatment. Those SNPs where no associations were found (Fisher's exact test) in relation to outcome were omitted from the final analysis (odds ratios, univariable estimation with $95 \%$ confidence intervals).

To measure the self-reported experience of burning, itching and irritation, a VAS was used, where 0 was no inconvenience and 10 was the worst possible. The results of the VAS score was dichotomized to no burning/burning (VAS $=0$ or $\mathrm{VAS}>0$ ), no itching/itching (VAS $=0$ or VAS $>0$ ) and no irritation/irritation (VAS $=0$ or VAS $>0$ ). The rationale for this dichotomization was that most of the patients reported low values on the scales.

The RTOG scores (Figure 2) were dichotomized in the analysis to RTOG 0/1 (no or mild ARSR) versus RTOG 2 to 4 (severe ARSR). The statistical software for genetic analysis was SAS ${ }^{\circledR}$ Genomics for Windows, ver.9.4 and JMP ${ }^{\circledR}$ Genomics for Windows, ver. 7.0. (SAS Institute Inc., Cary, NC, USA).

\section{Results}

Assessment of ARSR and related symptoms. It was possible to evaluate the acute symptoms of itching, burning and irritation as well as RTOG scoring for all 119 of the patients.

None of the patients were assessed as having any grade of ARSR nor did they report any related symptoms during the first RT week (data not shown). During the final week of RT, all patients were assessed as having ARSR, mostly scored as RTOG 1 or 2 . The median score for burning and irritation was 2 , whereas it was higher for irritation, with a median of 5 . At this time, many of the patients $(n=97,82 \%)$ reported itching (VAS scores ranging from 0 to 10), while $96(81 \%)$ reported irritation. About half of the patients $(n=64,53 \%)$ reported a burning sensation from the irradiated skin (Figure 2).

Fourteen women (12\%) were current smokers and 26 (23\%) had previously been treated with chemotherapy. Neither smoking status nor chemotherapy before RT had an influence on acute toxicity of the skin. No association was found between high body mass index and severe ARSR between VAS scores for related symptoms or RTOG score (data not shown).

SNPs and ARSR. Out of the 114 women for whom SNP analysis was possible, $77(68 \%)$ were prescribed topical 
Table II. Single nucleotide polymorphisms (SNPs) of genes analyzed in this study

\begin{tabular}{|c|c|c|}
\hline Gene & SNP & Encoded protein \\
\hline$I F N G$ & rs2069705 & Interferon gamma \\
\hline$E G F R$ & rs2293347 & Epidermal growth factor receptor \\
\hline ESR1 & rs2234693 & Estrogen receptor \\
\hline$T N F A$ & rs1800629 & Tumour necrosis factor -alfa \\
\hline$T N F A$ & rs 1800610 & Tumour necrosis factor -alfa \\
\hline$A B C A 1$ & rs2230806 & ATP-binding cassette transporter A1 \\
\hline CCL5 & rs2107538 & Chemokine (C-C motif) ligand 5 \\
\hline$X R C C 2$ & rs2040639 & $\mathrm{X}$-Ray repair cross-complementing protein 2 \\
\hline FGFR4 & rs2011077 & Fibroblast growth factor receptor 4 \\
\hline LIG4 & rs1805386 & DNA ligase 4 \\
\hline MTHFR & rs 1801133 & Methylenetetrahydrofolate reductase \\
\hline$C R P$ & rs 1800947 & C-reactive protein \\
\hline$B R C A 1$ & rs1799966 & Breast cancer 1 \\
\hline RAD52 & rs11571424 & DNA repair protein RAD 52 homolog \\
\hline CASP9 & rs1052576 & Caspase 9, apoptosis-related cysteine peptidase \\
\hline$C C L 2$ & rs2530797 & Chemokine (C-C motif) ligand 2 \\
\hline$X R C C 1$ & rs25487 & X-ray repair cross complementing protein 1 \\
\hline$C D K N 2 A$ & rs3088440 & Cyclin-dependent kinase inhibitor $2 \mathrm{~A}$, multiple tumour suppressor 1 \\
\hline CCND3 & rs3218086 & Cyclin D3 \\
\hline GSTP1 & rs1695 & Glutathione S-transferase gene class P1 \\
\hline$M M P 2$ & rs243865 & Matrix metallopeptidase 2 \\
\hline$B R C A 2$ & rs144848 & Breast cancer 2 \\
\hline$P R K D C$ & rs1231204 & DNA-activated protein kinase \\
\hline IL2 & rs6822844 & Interleukin 2 \\
\hline PRF1 & rs3758562 & Perforin 1 (pore forming protein) \\
\hline IL12RB2 & rs3790568 & Interleukin 12 receptor, beta 2 \\
\hline$A B C C 5$ & rs7636910 & Multidrug resistance-associated protein 5 \\
\hline$C C L 2$ & rs1024611 & Chemokine (C-C motif) ligand 2 \\
\hline$E G F$ & rs4444903 & Epidermal growth factor \\
\hline ATM & rs1801516 & Ataxia telangiectasia mutated \\
\hline
\end{tabular}

corticosteroid cream ( $0.1 \%$ Betametasone) during RT. The remaining 37 women $(32 \%)$ were recommended only the moisturizing cream (Essex ${ }^{\circledR}$ ) throughout the period of RT (Figure 3). After compensating for multiple testing, the following results remained statistically significant: One SNP, rs2069705, located in the interferon gamma (IFNG) gene was associated with itching. Another, rs 2040639 located in the $\mathrm{x}$-ray repair cross complementing 2 gene (XRCC2) was found to be associated with burning (Table III).

\section{Discussion}

All women in this study experienced ARSR-related symptoms during the last week of RT for BC. We found evidence for individual genetic variations to be linked to ARSR and related symptoms. Skin reactions differed substantially between different individuals in this analysis. This has raised the hypothesis that genetic background may influence ARSR, along with other factors such as breast size, body mass index, smoking and the modality of RT (25-27).
The evidence for individual genetic variations associated with ARSR and related symptoms among this mainly Swedish patient cohort was investigated. Two SNPs out of 28 studied genes (IFNG and XRCC2) were found possibly to be associated with ARSR. The gene XRCC2 has previously been shown to be involved in the repair of radiation-caused DNA damage (28). In this analysis, XRCC2 rs2040639 was found to be associated with burning. One immune response gene, IFNG, was associated with ARSR. IFNG rs2069705 was found to be associated with itching. The IFNG rs2069750 encoded protein was found to have significant immunoregulatory functions (29). Thus, besides the statistically significant associations found (Table III), there is a biological rationale for the two SNPs found to be associate with ASRS. We have not found evidence in the literature contradicting our results for ARSR. Most published studies were concerned with late skin reactions of RT [reviewed in (30)].

The use of moisturizing creams and potent corticosteroid creams are common in RT (31). In this study, a potent corticosteroid cream was prescribed, in some cases after the attending nurse assessed the irradiated skin using the RTOG 


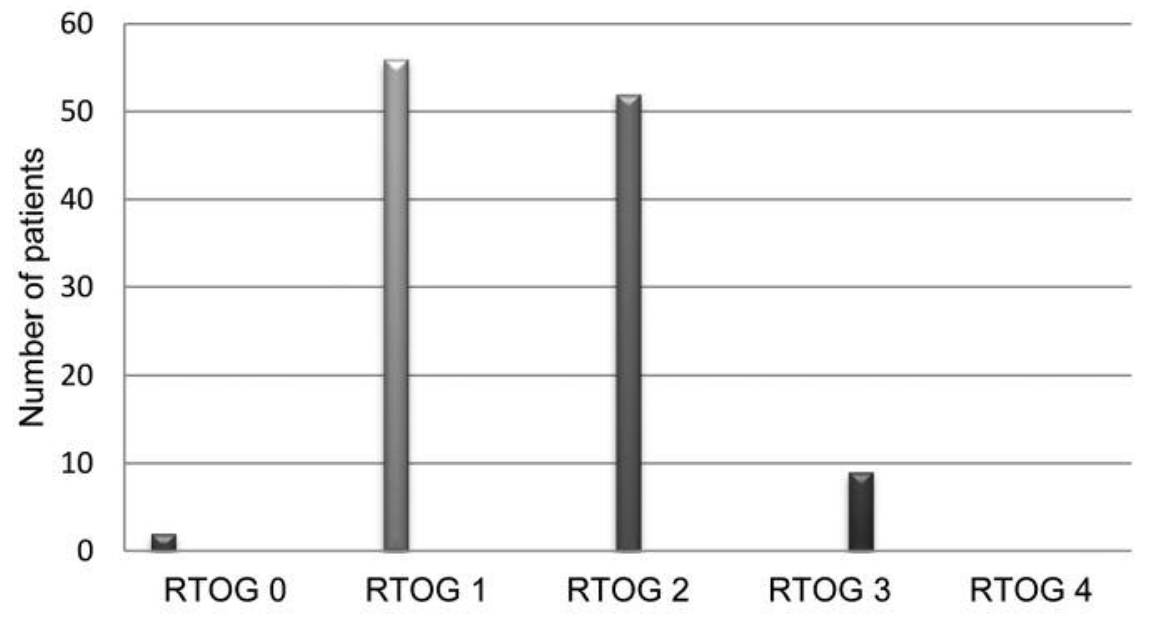

Figure 2. Frequency of radiation-induced side-effects in 119 females during radiotherapy for breast cancer according to classification by the Radiation Therapy Oncology Group (RTOG) scoring system for acute radiotherapy-induced dermatitis. RTOG 0: No toxicity observed, no erythema, desquamation or pain. RTOG 1: Faint, dull, or bright erythema, psilosis, dry desquamation, mild oedema. RTOG 2: Severe erythema, at least one moist desquamation of small size, moderate oedema. RTOG 3: Severe or confluent moist desquamation. RTOG 4: Ulceration, haemorrhage.

Table III. Genes and single nucleotide polymorphisms (SNPs) significantly associated with skin itching and burning as reactions to radiotherapy.

\begin{tabular}{|c|c|c|c|c|c|c|}
\hline \multirow[b]{2}{*}{ SNP } & \multirow[b]{2}{*}{ Genotype } & \multicolumn{2}{|c|}{ Symptom, n $(\%)^{*}$} & \multirow[t]{2}{*}{ OR } & \multirow[t]{2}{*}{$95 \% \mathrm{CI}$} & \multirow[t]{2}{*}{$p$-Value } \\
\hline & & Reaction & No reaction & & & \\
\hline \multirow[t]{3}{*}{ IFNG rs 2069705} & AA & $7(16 \%)$ & $37(84)$ & Ref & & 0.01 \\
\hline & $\mathrm{AG}$ & $23(44 \%)$ & $29(56)$ & 4.2 & $0.9-10.6$ & \\
\hline & GG & $7(37 \%)$ & $12(63)$ & 3.1 & $1.6-11.1$ & \\
\hline \multirow[t]{3}{*}{ XRCC2 rs 2040639} & $\mathrm{AA}$ & $14(58)$ & $10(42)$ & Ref & & 0.007 \\
\hline & AG & $31(50)$ & $31(50)$ & 6.7 & $1.9-23.7$ & \\
\hline & GG & $5(17)$ & $24(83)$ & 4.8 & $1.6-14.2$ & \\
\hline
\end{tabular}

CI: Confidence interval; IFNG: interferon gamma; OR: odds ratio; XRCC2: X-ray repair cross-complementing protein 2. *Itching for $I F N G$, burning for $X R C C 2$.

scale. Our results show that when a corticosteroid cream was given when ARSR occurred (Figure 3), the symptoms continued and were still reported at the end of the treatment. RT mobilises host immune response cell accumulation at the radiation site $(32,33)$. When these cells accumulate, corticosteroid might not be able to inhibit their mediated functions. Since corticosteroid cream influences immune response, the lack of effects of corticosteroid cream after the onset of ARSR supports our assumption (34).

The strengths of the study are that the patients were included consecutively, and the women were treated with similar RT regimens. We used validated instruments, patientreported and healthcare provider-reported data, as well as biological data, to provide information about ARSR. We report the findings according to the STrengthening the Reporting of Genetic Association studies in Radiogenomics (STROGAR) reporting when applicable (35).
Since the studied population in our case was relatively small, a larger study would more accurately determine the association between genetic background and ARSR after RT. This is emphasized by the impact of multiple testing making the significance more uncertain, since the standard errors are dependent on sample size and therefore a correction for multiple testing will sharpen the acceptable $p$-value limits, when the sample is relatively small. With a small sample size, the risk of missing important SNPs with a lower frequency is obvious. Other weaknesses of the study are that we used only two measurement points in addition to self-reported smoking status. Moreover, no assessments were performed after RT when ARSR typically peaks. The four patients who received a hypofractionated schedule presented no difference in reported outcomes due to similar radiation intensity or by chance. This could be due to the small number of patients treated with hypofractionation. 

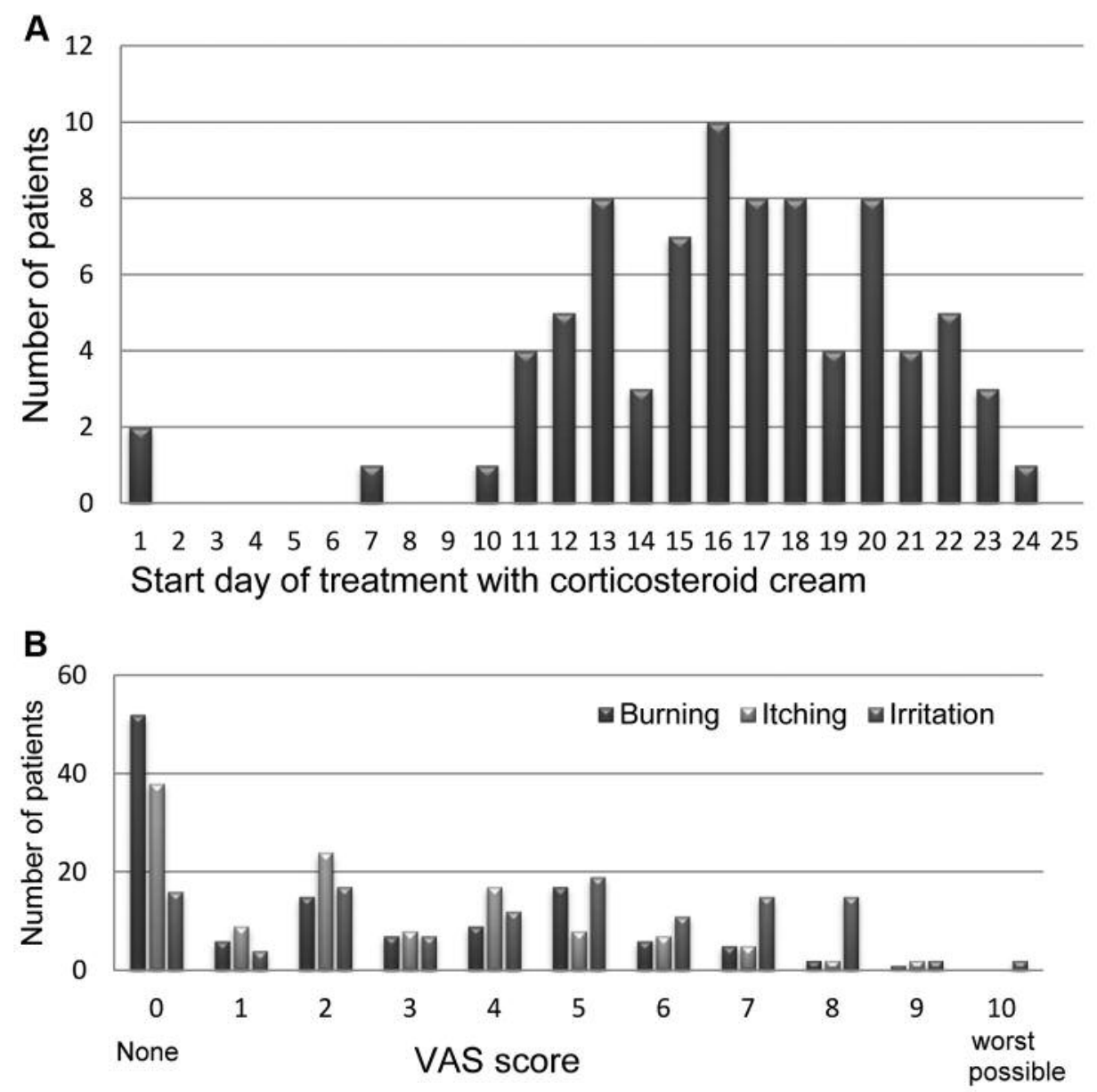

Figure 3. A: Starting day during radiotherapy of corticosteroid cream treatment of acute radiation skin reactions. Forty-two women did not receive corticosteroid cream. B: Self-reported symptoms of burning, itching and irritation, as reported on a 10-grade Visual Analog Scale (VAS) among 119 females during the last week of radiotherapy for breast cancer. The side-effects are irrespective of treatment with moisturizer or corticosteroid cream.

Even though new RT techniques, or developed devices for treatment have improved the accuracy of the RT, there are no guarantees that early symptoms such as ARSR will not be experienced during the treatment $(10,36)$.

However, our results support the hypothesis that the genetic background might influence individual differences in ARSR. The results should not be used for any change of RT but could rather be a future tool to individualize the intensity of care for the side-effects from the treatment. Future studies could be directed to explore the clinical relevance of bloodbased SNPs as prognostic biomarkers for ARSR.

\section{Conclusion}

The use of rapid and stable biomarkers to identify patients with an increased risk of ARSR would be helpful to personalize treatment and self-care advice. We detected an association between blood-based SNPs and ARSR in patients treated with adjuvant RT for BC. The possibility of using these specific SNPs in the clinical situation needs further investigation.

\section{Conflicts of Interest}

The Authors declare no conflicts of interest in regard to this study.

\section{Acknowledgements}

The Authors would like to thank the staff of the Radiotherapy Ward at the Department of Oncology, Ryhov County Hospital, Jönköping Sweden, as well as the staff at Laboratory Medicine and Tomas Axelsson for practical help and suggestions. The genotyping was carried at the SNP \& SEQ technology unit (www.genotyping.se) with support from Uppsala University and the Knut \& Alice Wallenberg Foundation of Uppsala, Sweden. This investigation was partly supported by Foundation for Clinical Cancer Research in Jönköping and Futurum Academy for Health and Care, Region Jönköping County, Sweden and FORSS-Medical Research Council of Southeast Sweden. 


\section{References}

1 Bolderston A, Lloyd NS, Wong RK, Holden L, RobbBlenderman L and Supportive Care Guidelines Group of Cancer Care Ontario Program in Evidence-Based C: The prevention and management of acute skin reactions related to radiation therapy: A systematic review and practice guideline. Support Care Cancer 14: 802-817, 2006.

2 De Langhe S, Mulliez T, Veldeman L, Remouchamps V, van Greveling A, Gilsoul M, De Schepper E, De Ruyck K, De Neve $\mathrm{W}$ and Thierens H: Factors modifying the risk for developing acute skin toxicity after whole-breast intensity modulated radiotherapy. BMC Cancer 14: 711, 2014.

3 Sharp L, Finnila K, Johansson H, Abrahamsson M, Hatschek T and Bergenmar M: No differences between Calendula cream and aqueous cream in the prevention of acute radiation skin reactions-results from a randomised blinded trial. Eur J Oncol Nurs 17: 429-435, 2013.

4 Russell NS, van Werkhoven E and Schagen SB: Quantification of patient-reported outcome measures of radiation-induced skin reactions for use in clinical trial design. Support Care Cancer 25: 67-74, 2017

5 Ulff E, Maroti M, Serup J and Falkmer U: A potent steroid cream is superior to emollients in reducing acute radiation dermatitis in breast cancer patients treated with adjuvant radiotherapy. A randomised study of betamethasone versus two moisturizing creams. Radiother Oncol 108: 287-292, 2013.

6 Sharp L, Johansson H, Landin Y, Moegelin IM and Bergenmar $\mathrm{M}$ : Frequency and severity of skin reactions in patients with breast cancer undergoing adjuvant radiotherapy, the usefulness of two assessment instruments-a pilot study. Eur J Cancer 47: 2665-2672, 2011.

7 Sharp L: Smoking among head and neck cancer patients: What can nurses do? ORL Head Neck Nurs 24: 10-16, 2006.

8 Song YZ, Han FJ, Liu M, Xia CC, Shi WY and Dong LH: Association between single nucleotide polymorphisms in XRCC 3 and radiation-induced adverse effects on normal tissue: A meta-analysis. PLoS One 10: e0130388, 2015.

9 Andreassen CN, Alsner J and Overgaard J: Does variability in normal tissue reactions after radiotherapy have a genetic basis? -Where and how to look for it. Radiother Oncol 64: 131-140, 2002.

10 Barnett GC, Kerns SL, Noble DJ, Dunning AM, West CM and Burnet NG: Incorporating genetic biomarkers into predictive models of normal tissue toxicity. Clin Oncol 27: 579-587, 2015.

11 Shen M, Hung RJ, Brennan P, Malaveille C, Donato F, Placidi D, Carta A, Hautefeuille A, Boffetta $\mathrm{P}$ and Porru S: Polymorphisms of the DNA repair genes XRCC1, XRCC3, XPD, interaction with environmental exposures and bladder cancer risk in a case-control study in northern Italy. Cancer Epidemiol Biomarkers Prev 12: 1234-1240, 2003.

12 Waldman SA and Terzic A: Managing the innovation supply chain to maximize personalized medicine. Clin Pharmacol Ther 95: 113-118, 2014.

13 Jurgensmeier JM, Eder JP and Herbst RS: New strategies in personalized medicine for solid tumors: Molecular markers and clinical trial designs. Clin Cancer Res 20: 4425-4435, 2014.

14 Miller RC, Schwartz DJ, Sloan JA, Griffin PC, Deming RL anders JC, Stoffel TJ, Haselow RE, Schaefer PL, Bearden JD, 3rd, Atherton PJ, Loprinzi CL and Martenson JA: Mometasone furoate effect on acute skin toxicity in breast cancer patients receiving radiotherapy: A phase III double-blind, randomized trial from the North Central Cancer Treatment Group N06C4. Int J Radiat Oncol Biol Phys 79: 1460-1466, 2011.

15 Schmuth M, Wimmer MA, Hofer S, Sztankay A, Weinlich G, Linder DM, Elias PM, Fritsch PO and Fritsch E: Topical corticosteroid therapy for acute radiation dermatitis: A prospective, randomized, double-blind study. Br J Dermatol 146: 983-991, 2002.

16 Pommier P, Gomez F, Sunyach MP, D'Hombres A, Carrie C and Montbarbon X: Phase III randomized trial of Calendula officinalis compared with trolamine for the prevention of acute dermatitis during irradiation for breast cancer. J Clin Oncol 22: 1447-1453, 2004.

17 Primavera G, Carrera M, Berardesca E, Pinnaro P, Messina M and Arcangeli G: A double-blind, vehicle-controlled clinical study to evaluate the efficacy of MAS065D (XClair), a hyaluronic acid-based formulation, in the management of radiation-induced dermatitis. Cutan Ocul Toxicol 25: 165-171, 2006.

18 Pinnix C, Perkins GH, Strom EA, Tereffe W, Woodward W, Oh JL, Arriaga L, Munsell MF, Kelly P, Hoffman KE, Smith BD, Buchholz TA and Yu TK: Topical hyaluronic acid $v s$. standard of care for the prevention of radiation dermatitis after adjuvant radiotherapy for breast cancer: Single-blind randomized phase III clinical trial. Int J Radiat Oncol Biol Phys 83: 1089-1094, 2012.

19 Bratengeier K, Oechsner M, Gainey M and Flentje M: Remarks on reporting and recording consistent with the ICRU reference dose. Radiat Oncol 4: 44, 2009.

20 Whelan TJ, Pignol JP, Levine MN, Julian JA, MacKenzie R, Parpia S, Shelley W, Grimard L, Bowen J, Lukka H, Perera F, Fyles A, Schneider K, Gulavita S and Freeman C: Long-term results of hypofractionated radiation therapy for breast cancer. N Engl J Med 362: 513-520, 2010.

21 Plataniotis G: Hypofractionated radiotherapy in the treatment of early breast cancer. World J Radiol 2: 197-202, 2010.

22 Cox JD, Stetz J and Pajak TF: Toxicity criteria of the Radiation Therapy Oncology Group (RTOG) and the European Organization for Research and Treatment of Cancer (EORTC). Int J Radiat Oncol Biol Phys 31: 1341-1346, 1995.

23 Dexter F and Chestnut DH: Analysis of statistical tests to compare visual analog scale measurements among groups. Anesthesiology 82: 896-902, 1995.

24 Hochberg Y: A sharper Bonferroni procedure for multiple tests of significance. Biometrika 75: 800-802, 1988.

25 Wells M, Macmillan M, Raab G, MacBride S, Bell N, MacKinnon K, MacDougall H, Samuel L and Munro A: Does aqueous or sucralfate cream affect the severity of erythematous radiation skin reactions? A randomised controlled trial. Radiother Oncol 73: 153-162, 2004.

26 Rudat V, Nour A, Ghaida SA and Alaradi A: Impact of hypofractionation and tangential beam IMRT on the acute skin reaction in adjuvant breast cancer radiotherapy. Radiat Oncol 11: $100,2016$.

27 Ulff E, Maroti M, Serup J, Nilsson M and Falkmer U: Prophylactic treatment with a potent corticosteroid cream ameliorates radiodermatitis, independent of radiation schedule: A randomized double blinded study. Radiother Oncol 122(1): 50-53, 2017. 
28 Silva SN, Tomar M, Paulo C, Gomes BC, Azevedo AP, Teixeira V, Pina JE, Rueff J and Gaspar JF: Breast cancer risk and common single nucleotide polymorphisms in homologous recombination DNA repair pathway genes $X R C C 2, X R C C 3$, NBS1 and RAD51. Cancer Epidemiol 34: 85-92, 2010.

29 Gao L, Bin L, Rafaels NM, Huang L, Potee J, Ruczinski I, Beaty TH, Paller AS, Schneider LC, Gallo R, Hanifin JM, Beck LA, Geha RS, Mathias RA, Barnes KC and Leung DY: Targeted deep sequencing identifies rare loss-of-function variants in IFNGRI for risk of atopic dermatitis complicated by eczema herpeticum. J Allergy Clin Immunol 136: 1591-1600, 2015.

30 Andreassen $\mathrm{CN}$ and Alsner J: Genetic variants and normal tissue toxicity after radiotherapy: A systematic review. Radiother Oncol 92: 299-309, 2009.

31 Feight D, Baney T, Bruce S and McQuestion M: Putting evidence into practice. Clin J Oncol Nurs 15: 481-492, 2011.

32 Park B, Yee C and Lee KM: The effect of radiation on the immune response to cancers. Int J Mol Sci 15: 927-943, 2014.

33 Aslam I, Sandoval LF and Feldman SR: What's new in the topical treatment of allergic skin diseases. Curr Opin Allergy Clin Immunol 14: 436-450, 2014.

34 Spies CM, Bijlsma JW, Burmester GR and Buttgereit F: Pharmacology of glucocorticoids in rheumatoid arthritis. Curr Opin Pharmacol 10: 302-307, 2010.
35 Barnett GC, Thompson D, Fachal L, Kerns S, Talbot C, Elliott RM, Dorling L, Coles CE, Dearnaley DP, Rosenstein BS, Vega A, Symonds P, Yarnold J, Baynes C, Michailidou K, Dennis J, Tyrer JP, Wilkinson JS, Gomez-Caamano A, Tanteles GA, Platte R, Mayes R, Conroy D, Maranian M, Luccarini C, Gulliford SL, Sydes MR, Hall E, Haviland J, Misra V, Titley J, Bentzen SM, Pharoah PD, Burnet NG, Dunning AM and West CM: A genome-wide association study (GWAS) providing evidence of an association between common genetic variants and late radiotherapy toxicity. Radiother Oncol 111: 178-185, 2014.

36 Deshmukh S, Sharan K, Fernandes DJ, Srinivasa VM, Yathiraj PH, Singh A and Reddy A: A study on dosimetric outcomes and acute toxicity of post mastectomy adjuvant hypofractionated radiotherapy for breast cancer. J Clin Diagn Res 10: XC05-XC08, 2016.

Received October 16, 2018

Revised October 29, 2018

Accepted October 31, 2018 


\section{Instructions for Authors 2018}

General Policy. ANTICANCER RESEARCH (AR) will accept original high quality works and reviews on all aspects of experimental and clinical cancer research. The Editorial Policy suggests that priority will be given to papers advancing the understanding of cancer causation, and to papers applying the results of basic research to cancer diagnosis, prognosis, and therapy. AR will also accept the following for publication: (a) Abstracts and Proceedings of scientific meetings on cancer, following consideration and approval by the Editorial Board; (b) Announcements of meetings related to cancer research; (c) Short reviews (of approximately 120 words) and announcements of newly received books and journals related to cancer, and (d) Announcements of awards and prizes.

The principal aim of AR is to provide prompt publication (print and online) for original works of high quality, generally within 1-2 months from final acceptance. Manuscripts will be accepted on the understanding that they report original unpublished works in the field of cancer research that are not under consideration for publication by another journal, and that they will not be published again in the same form. All authors should sign a submission letter confirming the approval of their article contents. All material submitted to AR will be subject to peer-review, when appropriate, by two members of the Editorial Board and by one suitable outside referee. All manuscripts submitted to AR are urgently treated with absolute confidence, with access restricted to the Managing Editor, the journal's secretary, the reviewers and the printers.The Editors reserve the right to improve manuscripts on grammar and style.

The Editors and Publishers of AR accept no responsibility for the contents and opinions expressed by the contributors. Authors should warrant due diligence in the creation and issuance of their work.

NIH Open Access Policy. The journal acknowledges that authors of NIH-funded research retain the right to provide a copy of the published manuscript to the NIH four months after publication in ANTICANCER RESEARCH, for public archiving in PubMed Central.

Copyright. Once a manuscript has been published in ANTICANCER RESEARCH, which is a copyrighted publication, the legal ownership of all published parts of the paper has been transferred from the Author(s) to the journal. Material published in the journal may not be reproduced or published elsewhere without the written consent of the Managing Editor or Publisher.

Format. Two types of papers may be submitted: (i) Full papers containing completed original work, and (ii) review articles concerning fields of recognisable progress. Papers should contain all essential data in order to make the presentation clear. Reasonable economy should be exercised with respect to the number of tables and illustrations used. Papers should be written in clear, concise English. Spelling should follow that given in the "Shorter Oxford English Dictionary".

Manuscripts. Submitted manuscripts should not exceed fourteen (14) pages (approximately 250 words per double - spaced typed page), including abstract, text, tables, figures, and references (corresponding to 4 printed pages). Papers exceeding 4 printed pages will be subject to excess page charges. All manuscripts should be divided into the following sections: (a) First page including the title of the presented work [not exceeding fifteen (15) words], full names and full postal addresses of all Authors, name of the Author to whom proofs are to be sent, key words, an abbreviated running title, an indication "review", "clinical", "epidemiological", or "experimental" study, and the date of submission. (Note: The order of the Authors is not necessarily indicative of their contribution to the work. Authors may note their individual contribution(s) in the appropriate section(s) of the presented work); (b) Abstract not exceeding 150 words, organized according to the following headings: Background/Aim - Materials and Methods/Patients and Methods - Results - Conclusion; (c) Introduction; (d) Materials and Methods/Patients and Methods; (e) Results; (f) Discussion; (g) Acknowledgements; (h) References. All pages must be numbered consecutively. Footnotes should be avoided. Review articles may follow a different style according to the subject matter and the Author's opinion. Review articles should not exceed 35 pages (approximately 250 words per double-spaced typed page) including all tables, figures, and references.

Figures. All figures should appear at the end of the submitted document file. Once a manuscript is accepted all figures and graphs should be submitted separately in either jpg, tiff or pdf format and at a minimum resolution of 300 dpi. Graphs must be submitted as pictures made from drawings and must not require any artwork, typesetting, or size modifications. Symbols, numbering and lettering should be clearly legible. The number and top of each figure must be indicated. Pages that include color figures are subject to color charges.

Tables. All tables should appear at the end of the submitted document file. Once a manuscript is accepted, each table should be submitted separately, typed double-spaced. Tables should be numbered with Roman numerals and should include a short title.

References. Authors must assume responsibility for the accuracy of the references used. Citations for the reference sections of submitted works should follow the standard form of "Index Medicus" and must be numbered consecutively. In the text, references should be cited by number. Examples: 1 Sumner AT: The nature of chromosome bands and their significance for cancer research. Anticancer Res 1: 205-216, 1981. 2 McGuire WL and Chamnes GC: Studies on the oestrogen receptor in breast cancer. In: Receptors for Reproductive Hormones (O' Malley BW, Chamnes GC (eds.). New York, Plenum Publ Corp., pp 113-136, 1973. 
Nomenclature and Abbreviations. Nomenclature should follow that given in "Chemical Abstracts", "Index Medicus", "Merck Index", "IUPAC -IUB", "Bergey's Manual of Determinative Bacteriology", The CBE Manual for Authors, Editors and Publishers (6th edition, 1994), and MIAME Standard for Microarray Data. Human gene symbols may be obtained from the HUGO Gene Nomenclature Committee (HGNC) (http://www.gene.ucl.ac.uk/). Approved mouse nomenclature may be obtained from http://www.informatics.jax.org/. Standard abbreviations are preferable. If a new abbreviation is used, it must be defined on first usage.

Clinical Trials. Authors of manuscripts describing clinical trials should provide the appropriate clinical trial number in the correct format in the text.

For International Standard Randomised Controlled Trials (ISRCTN) Registry (a not-for-profit organization whose registry is administered by Current Controlled Trials Ltd.) the unique number must be provided in this format: ISRCTNXXXXXXXX (where XXXXXXXX represents the unique number, always prefixed by "ISRCTN"). Please note that there is no space between the prefix "ISRCTN" and the number. Example: ISRCTN47956475.

For Clinicaltrials.gov registered trials, the unique number must be provided in this format: NCTXXXXXXXX (where XXXXXXXX represents the unique number, always prefixed by 'NCT'). Please note that there is no space between the prefix 'NCT' and the number. Example: NCT00001789.

Ethical Policies and Standards. ANTICANCER RESEARCH agrees with and follows the "Uniform Requirements for Manuscripts Submitted to Biomedical Journals" established by the International Committee of Medical Journal Editors in 1978 and updated in October 2001 (www.icmje.org). Microarray data analysis should comply with the "Minimum Information About Microarray Experiments (MIAME) standard". Specific guidelines are provided at the "Microarray Gene Expression Data Society" (MGED) website. Presentation of genome sequences should follow the guidelines of the NHGRI Policy on Release of Human Genomic Sequence Data. Research involving human beings must adhere to the principles of the Declaration of Helsinki and Title 45, U.S. Code of Federal Regulations, Part 46, Protection of Human Subjects, effective December 13, 2001. Research involving animals must adhere to the Guiding Principles in the Care and Use of Animals approved by the Council of the American Physiological Society. The use of animals in biomedical research should be under the careful supervision of a person adequately trained in this field and the animals must be treated humanely at all times. Research involving the use of human foetuses, foetal tissue, embryos and embryonic cells should adhere to the U.S. Public Law 103-41, effective December 13, 2001.

Submission of Manuscripts. Please follow the Instructions for Authors regarding the format of your manuscript and references. Manuscripts must be submitted only through our online submission system at: http://www.iiar-submissions.com/login.html In case a submission is incomplete, the corresponding Author will be notified accordingly. Questions regarding difficulties in using the online submission system should be addressed to: email: journals@iiar-anticancer.org

Galley Proofs. Unless otherwise indicated, galley proofs will be sent to the corresponding Author of the submission. Corrections of galley proofs should be limited to typographical errors. Reprints, PDF files, and/or Open Access may be ordered after the acceptance of the paper. Authors of online open access articles are entitled to a complimentary online subscription to Anticancer Research for the current year and all previous digital content since 2004. Requests should be addressed to the Editorial Office. Galley proofs should be returned corrected to the Editorial Office by email within two days.

\section{Specific information and additional instructions for Authors}

1. Anticancer Research (AR) closely follows the new developments in all fields of experimental and clinical cancer research by (a) inviting reviews on topics of immediate importance and substantial progress in the last three years, and (b) providing the highest priority for rapid publication to manuscripts presenting original results judged to be of exceptional value. Theoretical papers will only be considered and accepted if they bear a significant impact or formulate existing knowledge for the benefit of research progress.

2. Anticancer Research will consider the publication of conference proceedings and/or abstracts provided that the material submitted fulfils the quality requirements and instructions of the journal, following the regular review process by two suitable referees.

3. An acknowledgement of receipt, including the article number, title and date of receipt is sent to the corresponding author of each manuscript upon receipt. If this receipt is not received within 20 days from submission, the author should call or write to the Editorial Office to ensure that the manuscript (or the receipt) was not lost in the mail or during electronic submission.

4. Each manuscript submitted to AR is sent for review in confidence to two suitable referees with the request to return the manuscript with their comments to the Editorial Office within 12 days from receipt. If reviewers need a longer time or wish to send the manuscript to another expert, the manuscript may be returned to the Editorial Office with a delay. All manuscripts submitted to AR, are treated in confidence, without access to any person other than the Managing Editor, the journal's secretary, the reviewers and the printers. 
5. All accepted manuscripts are peer-reviewed and carefully corrected in style and language, if necessary, to make presentation clear. (There is no fee for this service). Every effort is made (a) to maintain the personal style of the author's writing and (b) to avoid change of meaning. Authors will be requested to examine carefully manuscripts which have undergone language correction at the pre-proof or proof stage.

6. Authors should pay attention to the following points when writing an article for AR:

- The Instructions to Authors must be followed in every detail.

- The presentation of the experimental methods should be clear and complete in every detail facilitating reproducibility by other scientists.

- The presentation of results should be simple and straightforward in style. Results and discussion should not he combined into one section, unless the paper is short.

- Results given in figures should not be repeated in tables.

- Figures (graphs or photographs) should be prepared at a width of 8 or $17 \mathrm{~cm}$ with legible numbers and lettering.

- Photographs should be clear with high contrast, presenting the actual observation described in the legend and in the text. Each legend should provide a complete description, being self-explanatory, including technique of preparation, information about the specimen and magnification.

- Statistical analysis should be elaborated wherever it is necessary. Simplification of presentation by giving only numerical or $\%$ values should be avoided.

- Fidelity of the techniques and reproducibility of the results, should be points of particular importance in the discussion section. Authors are advised to check the correctness of their methods and results carefully before writing an article. Probable or dubious explanations should be avoided.

- Authors should not cite results submitted for publication in the reference section. Such results may be described briefly in the text with a note in parenthesis (submitted for publication by... authors, year).

- The References section should provide as complete a coverage of the literature as possible including all the relevant works published up to the time of submission.

- By following these instructions, Authors will facilitate a more rapid review and processing of their manuscripts and will provide the readers with concise and useful papers.

7. Following review and acceptance, a manuscript is examined in language and style, and galley proofs are rapidly prepared. Second proofs are not sent unless required.

8. Authors should correct their galley proofs very carefully and preferably twice. An additional correction by a colleague always proves to be useful. Particular attention should be paid to chemical formulas, mathematical equations, symbols, medical nomenclature etc. Any system of correction marks can be used in a clear manner, preferably with a red pen. Additions or clarifications are allowed provided that they improve the presentation but do not bring new results (no fee).

9. Articles submitted to AR may be rejected without review if:

- they do not fall within the journal's policy.

- they do not follow the instructions for authors.

- language is unclear.

- results are not sufficient to support a final conclusion.

- results are not objectively based on valid experiments.

- they repeat results already published by the same or other authors before the submission to AR.

- plagiarism is detected by plagiarism screening services.

(Rejection rate (2016): 66\%).

10. Authors who wish to prepare a review should contact the Managing Editor of the journal in order to get confirmation of interest in the particular topic of the review. The expression of interest by the Managing Editor does not necessarily imply acceptance of the review by the journal.

11. Authors may inquire information about the status of their manuscript(s) by calling the Editorial Office at $+30-22950-53389$, Monday to Friday 9.00-16.00 (Athens time), or by sending an e-mail to journals@iiar-anticancer.org

12. Authors who wish to edit a special issue on a particular topic should contact the Managing Editor.

13. Authors, Editors and Publishers of books are welcome to submit their books for immediate review in AR. There is no fee for this service.

(This text is a combination of advice and suggestions contributed by Editors, Authors, Readers and the Managing Editor of AR).

Copyright $(2018$ - International Institute of Anticancer Research (G.J. Delinasios). All rights reserved (including those of translation into other languages). No part of this journal may be reproduced, stored in a retrieval system, or transmitted in any form or by any means, electronic, mechanical, photocopying, microfilming, recording or otherwise, without written permission from the Publisher. 